\title{
O processo de fetichização da comunicação em Marx frente às problemáticas das fake news
}

\author{
The process of fetishization of communication in Marx in the face of fake \\ news
}

\author{
MARCOS A. MANTOVANI ${ }^{1}$ \\ KATIA R. SALOMÃO
}

\begin{abstract}
Resumo: O presente trabalho possui o objetivo de analisar face ao direito à informação, a comunicação em seu caráter discursivo, instrumentalizado e fetichizado, no qual a mesma assume a condição mercantilizada e suas manifestações imbricadas nas fake news. Para isso, buscou-se em Karl Marx compreender a comunicação enquanto seu caráter discursivo e instrumentalizado por meio dos conceitos de fetiche da mercadoria, contrastando ao conceito de domesticação pela comunicação de Chomsky. Ao fim, propôs-se ainda analisar as contradições presentes nos fake news, como fato notório que corrobora no processo de lícito de direito à informação.
\end{abstract}

Palavras-chave: Mercantilização. Instrumentalização. Informação. Fake News.

Abstract: The present work has the objective of analyzing with the right to information, the communication in its discursive, instrumentalized and fetishized character, in which the same assumes the mercantilized condition and its manifestations together in the fake news. For this sake, Karl Marx sought to understand communication as its discursive and instrumental character through the concepts of fetish of the commodity, contrasting to the concept of domestication by communication from Chomsky. At the end, it was also proposed to analyze the contradictions present in fake news, as a notorious fact that corroborates in the lawful process of right to information.

Keywords: Mercantilization. Instrumentation. Information. Fake News.

\section{Introdução}

É notório considerar que desde o iluminismo a comunicação foi o elemento promotor da transformação social. No iluminismo surge a ideia de que a opinião pública tinha como principal objetivo conduzir a transformação, a emancipação e a libertação dos oprimidos, miseráveis e ignorantes.

Entretanto, na pós modernidade, esse conceito parece ter se perdido: afinal a comunicação é mais um instrumento para a disseminação do consumo, para a manipulação econômica, política ou social. Até ela, a opinião pública, antes na filosofia de Rousseau $(1973)^{3}$, tratada como vontade geral unida do povo, isto é o

\footnotetext{
${ }^{1}$ Universidade Estadual de Londrina - UEL. E-mail: mantovani5oo@hotmail.com

${ }^{2}$ Centro Universitário de Cascavel - UNIVEL. Doutoranda em Filosofia pela Universidade Estadual do Oeste do Paraná - UNIOESTE. E-mail: salomao@univel.br.

${ }^{3}$ Rousseau (1973, p. 85) fazia a distinção entre vontade de todos, que pode errar, e vontade geral, que nunca erra porque só tem em mira o interesse comum. Essa concepção da filosofia rousseauniana é controversa e muito discutida entre os estudiosos do tema, e não temos o intuito de conduzi-la a
} 
cerne da ideia de democracia, foi tomada de empréstimo pelo capitalismo e convertida em opinião midiática, capaz de projetar necessidades criadas para o indivíduo moderno.

Mas, ainda existe diante deste processo de coisificação da informação, a possibilidade de garantir direito à informação licita capacitada em tornar-se geradora de esclarecimento social, popular ou comunitário (?).

O advento a era da informação, criadora de uma rede virtual global de comunicação, a internet, contribui para o processo de direito à informação isenta da racionalidade sistêmica (?). Acredita-se, que a era da informação, apesar de ter facilitado em muito o processo de comunicação, tem também seus aspectos discursivos fetichizados pela racionalidade do sistêmica. Afinal, as fake news (notícias falsas) denotam claramente as condições da informação coisificada em mercadoria.

\subsection{Fetichização da comunicação em Marx e a problemática dos fake news}

Versa na Constituição brasileira o direito à informação para todos os cidadãos. Do ponto de vista formal, o direito a informação está integrado na constituição federal em seu artigo $5^{\circ}$ no âmbito dos direitos fundamentais, sendo ele uma das bases que sustentam a democracia brasileira.

No entanto, cada vez mais observa-se razões que levam ao questionamento desse aclamado direito fundamental do cidadão. Isto nota-se evidenciados no processo de transmutação, de simples folhetins para poderosos conglomerados empresariais, fomentando uma modificação crucial no conceito da informação, no qual a comunicação foi fetichizada tornando-se mercadoria.

Todavia, diante deste momento crucial, o da era da informação, no qual a celeridade da comunicação parecia convergir com as condições de serem disseminados num espaço virtual livre de impeditivos sistêmicos e isentos da mercantilização capitalista, desponta-se mais um paradoxo do mundo moderno: mais informação não significa esclarecimento.

Alguns poderiam manifestar a opinião simplificadora e generalista que o problema da disseminação do fake news como verdade está vinculada a falta de escolaridade e senso crítico do leitor. Contudo, pesquisa realizada na Universidade de Stanford ${ }^{4}$ em junho de 2016 revelou a ausência da capacidade de estudantes norte

uma analise de suas últimas consequências. Assim, A vontade geral será tomada como uma ideia que parece consistir em que, eliminando-se os interesses conflitantes, resta algum interesse próprio, compartilhado por todos.

4 Cf. CRAWFORD, 2018. Na notícia vinculada ao site da faculdade de Stanford além dos índices da pesquisa revelados por Crawford, fica aclarada que os fakes influenciaram os rumos das eleições americanas presidenciais. Esta é a prova cabal, da alienação e o controle das massas, afetando diretamente a essência democrática do Estado de Direito. 
americanos em verificar a validade de informações divulgadas na internet. Foram entrevistados 7.804 alunos dos ensinos fundamental, médio e superior, onde $40 \%$ não conseguiram detectar fake news. Diante deste contexto, de total perplexidade da informação, não se pode mais negar que até no espaço digital, a mesma está a serviço da manutenção da efetiva racionalidade econômica do sistema: afinal fake news são gerados de milhares em capital. A cada acesso do leitor o divulgador das notícias plantadas ganham em publicidade, e podem lucrar muito mais distorcendo os rumos da política, da economia, entre outros.

Mas, esse processo já havia sido denunciado por Marx na obra o Capital, na qual o seu primeiro capítulo está destinado à análise da mercadoria. Segundo Rubin (1980) em Marx, a análise do papel da mercadoria dentro do sistema capitalista é que permite determinar o caráter do trabalho, pois ele tem como objetivo entender a especificidade da mercadoria dentro do sistema, e, principalmente, a que se deve seu valor. Além disso, este valor é justamente o valor da manipulação das massas, de modo que a mesma esteja confortável e docilizada consumindo.

E em se tratando de mercadoria, o jornalismo transformou-se em uma poderosa ferramenta de construção de ideologias, as quais operam enquanto instrumentos de controle social. O fetiche da mercadoria já havia sido explicado por Marx (1992) quando tratou das relações de exploração do trabalho alienado. Atualmente, essa forma de opressão rompe com o ambiente do labor, indo além, isto é, invadindo, manipulando e alienando os indivíduos do mundo vivido.

Com o fetiche da mercadoria, do dinheiro e, especialmente, do salário, o mundo real, e não apenas a consciência que os homens (e mulheres) tomam deste mundo, é desfigurado e posto de cabeça para baixo. A consciência dos homens (e mulheres) não se põe ela própria de cabeça para baixo, ante ao contrário, é o mundo desfigurado e posto de cabeça para baixo pelo fetiche que deforma e inverte a consciência humana [...] é o mundo mágico e enfeitiçado do mercado, do dinheiro e da produção de mercadorias que enfeitiça e engana (ANTUNES, 2006, p. 2012).

No contexto da informação mercantilizada vem à tona a problemática apresentada como proposta de artigo: Em vista ao caráter discursivo instrumentalizado e fetichizado da comunicação, no qual a mesma assume a condição mercantilizada e suas manifestações, o fake news estariam imbricando diretamente no direito fundamental a informação (?). Afinal, um Estado de Direito que tem como base os direitos fundamentais do cidadão, perde sua essência de reconhecimento diante dos flagelos da efetivação dos mesmos: fato este que comprova a insuficiência democrática da existência social ocidental.

A informação a qual o cidadão tem direito deve ser lícita e verdadeira, não atendendo demandas políticas partidárias ou econômicas. Em outrora, no início da era moderna, em meados séculos XVIII e XIX, compreendia-se que a opinião pública 
emanada da informação, tinha como objetivo esclarecer, libertar e emancipar. Estes objetivos originários intrínsecos à informação parecem ter-se auto-atrofiado.

Ao contrário da libertação almejada, a opinião pública enquanto produto do lato senso comum, isto é, do cotidiano comum compartilhado pelos profissionais do jornalismo e cidadãos, conduz a informação à coisificando em produto.

De acordo com Bauman (2008), diante da sistemática do consumo desenfreado presente na esfera mercadológica atual, até mesmo a informação tornou-se produto a ser consumido pelo indivíduo. Bauman, em seu livro "Vida para o consumo: a transformação da pessoa em mercadoria" (2008) propõe pensar a respeito das elementares características do fetichismo que as mercadorias passam a exercer sobre os consumidores, fazendo-os não só se sentirem, mas portarem-se como mercadorias. Mas, este sociólogo também aponta que o principal problema evidencia-se quando a mercadoria torna-se a própria informação.

A sociedade de produtores, principal modelo da fase "sólida" da modernidade, foi basicamente orientada para a segurança. Nessa busca, apostou-se no desejo humano de um ambiente confiável, ordenado, regular, transparente e, como prova disso, duradouro, resistente ao tempo e seguro. Esse desejo era de fato uma matéria prima bastante conveniente e para que fossem construídos os tipos de estratégias de vida e padrões comportamentais indispensáveis à era do "tamanho é poder" e do "grande é lindo": uma era de fábricas e exércitos de massa, regras obrigatórias e conformidade às mesmas, assim como de estratégias burocráticas e panópticas de dominação que, em seu esforço para evocar disciplina e subordinação, basearam-se na padronização e rotinização do comportamento individual (BAUMAN, 2008, p. 42).

\subsection{A docilização da comunicação como processo ideológico}

Este discurso marxista permanece latente nos neomarxistas, dentre estes, pode-se apontar também a conceituação de Noam Chomsky. Um ponto crucial do seu discurso altamente crítico toma forma quando trata da domesticação da maioria através da informação fetichizada.

Por isso, faz sentido ressaltar a questão da ideologia enquanto instrumento de controle social. Afinal, ela é disseminada na comunicação estatal, midiática e até mesmo informal, promovendo a alienação total do público. Ela, a ideologia, converteu a comunicação em objeto a serviço do capital, malogrando o direito a informação ética e lícita assegurado constitucionalmente.

Em diversas situações, o poder dos conglomerados da comunicação provocam discussões que avultam os fatos reais, sendo a população induzida manipuladamente em questionar situações específicas, as quais favorecem os interesses escusos destas indústrias da comunicação, ou seja, são capacitadas em 
descreditar opositores ou ideais de acordo com seus interesses econômicos.

Chomsky ${ }^{5}$, em seu texto 'Mídia: propaganda política e manipulação' descreve essa realidade ao tecer suas considerações sobre a domesticação do rebanho. Ela é permanente, isto por que, a democracia inserida em uma crise que parece permanente, desde meados da Segunda Guerra Mundial, não tem força o suficiente para provocar a revolução como prevista e exaltada no Capital de Marx. Isso decorre do fato que:

A mercadoria é misteriosa simplesmente por encobrir as características sociais do próprio trabalho dos homens, apresentando-as como características materiais e propriedades sociais inerentes aos produtos do trabalho; por ocultar, portanto, a relação social entre os trabalhos individuais dos produtores e o trabalho total, [...]. Chamo a isto de fetichismo, que está sempre grudado aos produtos do trabalho, quando são gerados como mercadorias. É inseparável da produção de mercadorias (MARX, 1983 , p. 81$)$.

Por ser a mercadoria algo imanente ao trabalho, e o trabalho o meio pelo qual a sociedade se transforma a própria comunicação tornou-se um produto. A informação mesmo diante da crise constante e perene da democracia, apesar de saudável na visão de Chomsky (2014) não é capaz de provocar a transformação política, já que na própria população é domesticada por meio dos instrumentos de controle social. Os grupos de comunicação supramencionados alimentam a apatia, a obediência e a passividade.

As responsáveis pela domesticação do "rebanho de desorientados" são as ideologias, projetadas na comunicação de massa. Para Chomsky (2014), o poderio econômico tem força para manipular a massa que inconscientemente acata como verdade absoluta aquilo que lhe é transmitida seja via audiovisual, radiofônica ou escrita.

Por derradeiro, diante do espaço virtual de comunicação, os fake news se materializam como informação fetichizada em consumo, induzindo a distorção, corroborando com a manipulação, (vez que permitem uma paráfrase a Hannah Arendt, uma das grandes pensadoras do século XX), disseminando a 'banalidade do mal'.

\footnotetext{
${ }^{5}$ Chomsky, 2014 no texto "Mídia Propaganda Política e Manipulação" trata da realidade norte americana pós II Guerra Mundial que envolve diretamente o papel da mídia na política contemporânea. É um texto que fala de uma democracia de expectadores onde a massa de ignorantes precisa ser conduzida a um aparente sentido ativo, ou seja, a população precisa ter o sentimento de participação política, mesmo que seja um rebanho de desorientados. Parece, num primeiro momento, um tanto quanto estranho resgatar um pensador norte americano para falar da crise social, política e econômica no Brasil, entretanto, isto se faz salutar porque toda a reflexão suscitada na leitura de tal texto faz-se análoga a nossa realidade.
} 


\section{Considerações finais}

Todos estamos, indubitavelmente, submetidos a este processo no qual a comunicação parece imiscuir sua essência. Ela, já não está mais apta a promover a emancipação dos sujeitos através de sua potencialidade informativa. Marx e Chomsky corroboram no sentido de analisar os conceitos de mercantilização, que nos são incomensuravelmente caros. Tais pensadores perceberam que até mesmo a comunicação foi corroída pela dinâmica do Capital, sendo capazes de subverter o processo de tomada de decisão e de direitos sociais.

Embora, o objetivo originário dos dissidentes, dos promotores de uma contra cultura da comunicação, que era o prisma da transformação social, com o papel de malograr a chamada hegemonia política mercantilista da informação, com a era da informação virtualizada parece ter encontrado sua derradeira faceta.

Durante muito tempo, movimentos sociais em geral oprimidos por uma cultura capitalista/imperialista, se espelham na aglomeração de pessoas em torno de ideais sociológicos emancipadores, no intuito de combater a chamada 'pacificação' e proporcionar o direito à informação. Isto se dava por meio da informação direcionada e esclarecida, possibilitadoras de discussões esclarecedoras, ampliando o entendimento do conceito de formação de grupos em prol a defesa da emancipação social.

Sumariamente, acreditou-se diante do processo de mercantilização da informação próprio da pós modernidade, que somente por meio de movimentos sociais populares que encontrassem um espaço livre para o fluxo da informação, ou seja, de uma genuína ação comunitária, capacitada em direcionar a opinião pública de modo não deturpado, é que se tornava concreta a concepção de uma democracia social em sua essência.

O direito a informação, na rede virtual global de informação deveria seguir o objetivo genuíno da comunicação livre e libertária. Mas, diante dos fake news, o que considerar (?). Somente, podemos suspeitar de possíveis implicações do fake news no processo de fetichização da comunicação, como manifestação direta da negligência ao direito à informação, e, consequentemente, da distorção dos ideais do Estado de Direito e da democracia atual.

Suspeita-se que essa é a derradeira época, na qual pode-se compreender que a caverna $^{6}$ é a própria comunicação, quando a mesma se converte em notícias falsas, que tem apenas o intuito de gerar economicamente lucratividade irracional.

E na tentativa de expandir a caverna na qual a humanidade se encontra

\footnotetext{
${ }^{6}$ Fazemos referência à caverna de Platão, na qual as sombras são a 'verdades' aparentes projetadas nas paredes da caverna. Esta que é apenas o resultado aparente de uma projeção, bem como os fake news, que apresentam um conteúdo que parece verdadeiro, mas é mera aparência descritiva dos fatos.
} 
agrilhoada, os recursos financeiros são amplamente investidos, buscando através de modernos equipamentos, de novas tecnologias, solidificar a vida inventada e aparente em real, ou seja, o virtual torna-se finalmente o real. Mesmo assim, apesar de quase tudo indicar pela nulidade de pensamento do ser humano, ainda há esperança de que nem tudo está perdido. Trata-se da não alienação por meio da leitura. Em outras palavras, a autonomia da razão só pode ser alcançada por meio do descentramento, do desvelamento e do desencantamento das imagens celebradas como verdade real.

\section{Referências}

ANTUNES, J. “O fetiche forma-salário”. In: SOUZA, E. C. e alii. Ressonâncias filosóficas: entre o pensamento e ação. Cascavel, PR: EDUNIOESTE, 2006.

BAUMAN, Z. Vida para consumo: a transformação de pessoas em mercadoria. Rio de Janeiro: Jorge Zahar, 2008.

CHOMSKY, N. Poder e terrorismo. Rio de Janeiro: Record, 2005.

. Mídia: propaganda política e manipulação. São Paulo: Martins Fontes, 2014.

CRAWFORD, K. Stanford study examines fake news and the 2016 presidential election.

Disponível em:< https://news.stanford.edu/2017/o1/18/stanford-study-examines-fake-news2016-presidential-election/>. Acesso em: 24, jul/2018.

MARX, K. Salário, preço e lucro. São Paulo: Abril Cultural, 1982. (Coleção Os Economistas). O capital: crítica da economia política. São Paulo: Nova Cultural, 1983. Sociologia. 7. ed. São Paulo: Ática, 1992.

ROUSSEAU, J-J. Do contrato social: ou princípios do direito político. São Paulo: Abril Cultural, 1973.

RUBIN, I. I. A teoria marxista do valor. São Paulo: Brasiliense, 1980.

Submissão: 24.10.2018 / Aceite: 24.11.2018 